\title{
Immunopathology of Chagas Disease - A Historical Overview
}

\author{
WL Tafuri \\ Departamento de Patologia Geral, ICB, Universidade Federal de Minas Gerais, Caixa Postal 486, 31270-901 \\ Belo Horizonte, MG, Brasil
}

Key words: Chagas disease - immunophatology

There are several factors which directly or indirectly contribute to lesions produced by infection with Trypanosoma cruzi. Some of these factors are inherent to the parasite (initial parasitehost interactions which are ligand-specific, pleomorphism, tropism, virulence, genetic and antigenic constitution, parasite number of the inoculum, reinfection, parasite strains, clonal selection, mixed populations, etc.); others are related to the host (genetic constitution, sex, age, race, nutrition, immune response, professional macrophages and non-permissible cells, muscle cells, peripheral and central neuroglia, fibroblasts, mast cells and others). As in other infectious diseases, in Chagas disease, the mechanisms by which $T$. cruzi induces lesion are multi-faceted. Depending on these mechanism anatomo-clinical forms will or will not appear. By whatever means T. cruzi infects its host, any cell of different tissues and organs can be randomly infected. Several molecules ( 80 to $200 \mathrm{kDa}$ ) responsible for cell adhesion and penetration have been identified on the surface of the parasite (Bosghetti et al. 1987, Alves 1996). After gaining access into the cell, the parasite multiplies and, at this initial phase of the infection, are very aggressive since there is no immunity and no inflammatory reaction around parasitized cells. The escape from the parasitophorus vacuole into the host-cell is due to the action of a hemolysin which functions in acid $\mathrm{pH}$. Thus, the host-cell bursts and both epi and tripomastigote parasite forms as well as organelles are released in the interstitium and work as an antigenic mosaic which will induce a rapid, parasite-specific and cell-mediated immune reaction. In consequence, an acute and focal inflammatory reaction with the exudation of mononucleated cells appears around areas of necrosis. This is seen most notably as myocarditis, myositis (both smooth and striated muscles), periganglionitis,

Fax:+55-031-499.2889

E-mail: wtafuri@mono.icb.ufmg.br

Received 9 June 1999

Accepted 9 August 1999 ganglionitis, perineuritis and neuritis. With the progression of the immune response, parasite levels in blood and tissues drop. Nevertheless, the parasite is not completely eliminated, even in the presence of a Th1 lymphocyte response (IL-2 and IFN gamma) or circulating IgM and IgG antibodies.

The mechanisms underlying the ability of the parasite to escape the immune response are very complex and not completely understood. Several ideas have been pursued to explain such phenomenon, including the complexity and diversity of receptors needed for internalization, the escape from complement-mediated lysis, the endocytosis of antibodies by the parasite, the genetic polymorphism, the expression of several antigenic immunodeterminants at the same time, the antigenic mimetism, the suppression of the release of IFN gamma by Th1 lymphocytes, the polyclonal activation of $\mathrm{T}$ and $\mathrm{B}$ cells and the excessive production of TNF $\alpha$. Although T. cruzi can infect any cell type, there are strains with a greater tropism for certain cells, tissues and organs. Thus, the different anatomo-clinical presentations of the disease will be determined by: (1) the tropism for different organs; (2) the intensity of parasitism; (3) the intensity of the inflammatory response; (4) the build-up and evolution of the immune response. Depending on these factors, anatomo-clinical forms, such as the cardiac or digestive forms, will develop into chronic fibrosing myocarditis with heart failure and/or in the megas, although tissue parasitism is almost absent. However a focal and/ or diffuse inflammation is intense. Here, fibrosis (focal and diffuse fibrilopoesis) is the new observation not noticed in the acute forms. In our view, tissue fibrosis associated with parasympatic denervation is the major cause for the progressive functional loss of the affected organ (Tafuri 1979).

Although there is a vast literature about the subject, there is little known about the intimate immunological mechanisms which control the changes in local and general reactivity of the organisms during the evolution of the chagasic infection. For this reason, the reasons underlying the natural history of Chagas disease is still not known. The focal acute inflammation evolves to an asymp- 
tomatic chronic phase and the parasitism is suppose controlled by multiple mechanisms which include, complement fixation, antibodies and citotoxic lymphocytes (CD8+) which are activated by Th1-like CD4+ lymphocytes (Gazzinelli et al. 1998). In fact, the importance of cell-mediated immunity is exemplified by the observation that the parasitism becomes intense if any immunosuppression occurs (e.g. Aids, cyclophosphamide, and radiotherapy). Even though the cell-mediated immune response is effective, what are the underlying factors responsible for the modulation of the immune response in such way that 10-20 years after the initial infection the patient (20-30\% of patients) evolves to significant organ malfunction, characterized by the megas and chronic fibrosing myocarditis? Even in these new anatomical forms of the disease, there is a low degree of parasitism, in contrast to an intense inflammation reaction. It remains the possibility that autoimmune mechanisms play a role in disease progression. Indeed, the role of autoimmunity in the genesis of the chronic chagasic myocarditis is supported by several authors including Santos-Buch and Acosta (1985), Kierzenbaum (1986), Santos et al. (1992), but contested by others Tarleton et al. (1997). Considering these ideas it appears that parasites and autoantigens are involved in the Chagas disease (Higushi et al. 1993, Reis et al. 1993, Cunha-Neto et al. 1995).

As one reads the vast literature on Chagas disease, it is easy to note an almost complete absence of studies about the structured and non-structured components of the extracelular matrix and their relation to the immune response in the acute and chronic phases of human and experimental Chagas. The extracelular matrix components of the heart are made of an intricate tridimensional net involving each cardiac muscle cell. These components are in constant and dynamic changes, which depend on a range of physiologic, homeostatic and immunological stimulus, such as those after aggression by pathogens (e.g. T. cruzi), and those of any fibrosing disease. As the extracelular matrix is in intimate contact with the cardiomyocytes, it is easy to understand that any quantitative or qualitative change in matrix expression may induce functional alterations of cardiomyocytes and the heart. Fibroblasts are the main cell type, which synthesize and release the different types of collagens where the alpha- $\beta 1$ integrin (metaloprotease) plays an important role in the functions of the cell matrix (Kanekar 1998). Integrins are one of the four families of specific transmembrane receptors that are attached to the citoeskeleton. They are responsible for the transmission of signals from the matrix to the cells. It is our working hypothesis on Chagas disease that the immune response deviations are directly involved in the alterations of extracelular matrix. Macrophages, lymphocytes, fibroblasts and cytokines may play a central role in this context.

\section{REFERENCES}

Alves MJM.1996. Members of the Tc-Bb protein family from Trypanosoma cruzi and adhesion proteins. Braz J Med Biol Res 29: 831-833.

Bosghetti MA, Piras MM, Piras HD 1987. The interaction of Trypanosoma cruzi surface protein with vero cells and its relationship with parasite adhesion. $\mathrm{Mol}$ Biol Parasitol 24: 175-184.

Cunha-Neto E, Duranti M, Gruber A, Zingales B, Messia I, Stoff N, Belloti G, Patarroyo ME, Pellegi F, Kalil J 1995. Autoimmunity in chagas disease cardiopaty: Biological revelance of cardiac myosin-specific epitop crossreactive to an immunodominant Trypanosoma cruzi. Proc Natl Acad Sci USA 98: 35413545

Gazzinelli RT, Talvani A, Camargo MM, Santiago HC, Oliveira MAP, Vieira LQ, Martins GA, Aliberti JCS, Silva JS 1998. Induction of cell-mediated immunity during stages of infection with intracellular protozoa. Braz J Med Biol Res 31: 89-104.

Higuchi MT, Gutierrez PS, Aiello VD, Palomino S, Boschi E, Kalil J, Belloti G, Pillegi F 1993. Immunochemical characterization of infiltrating cells in human chronic chagasi myocarditis comparision with myocardial rejection process. Virchow Arch (A), 423: $157-160$

Kanekar S, Hinozanne T, Teracio L, Borg TK 1998. Cardiac fibroblast form and function. Cardio-Pathol 7: $127-133$

Kirzenbaun F 1986. Autoimmunity in Chagas disease. J Parasitol 72: 201-211

Reis DD, Jonnes EM, Tostes S, Lopes ER, Gazinneli J, Colley DG, Curley TL 1993. Characterization of inflammatory infiltrates in chronic chagasi myocardial lesions. Presence of tumor necrosis factor a cells and dominance of granzyme A CD8 lymphocytes. Am J Trop Med Hyg 48: 637-644.

Santos-Buch CA, Acosta AM 1985. Pathology of Chagas disease, p. 145-184. In I Tizard, Immunology and Pathogenesis of Trypanosomiasis, CRC Press, Boca Raton, Fl.

Santos RR, Rossi MA, Laus JL, Silva JS, Savino W, Mengel J 1992. Anti-CD4 abrogates rejection and reestablishes long term tolerance to syngenic newborn hearts in mice chronically infected with Trypanosoma cruzi. J Exp Med 175: 29-39.

Tafuri WL 1979. Biology of Kinetoplatidae, Vet. II, p. 547-610, Acad. Press.

Tarleton RL, Zhang L, Downs MO 1997. Autoimmune rejection of neonatal transplants in experimental Chagas disease is a parasite-specific response to injected host tissue. Proc Natl Acad Sci USA 94: 3932-3937. 